\title{
Phylogenetic Distribution, Ultrastructure, and Function of Bacterial Flagellar Sheaths
}

\author{
Joshua Chu ${ }^{1}$, Jun Liu ${ }^{2}$ and Timothy R. Hoover ${ }^{3, *}$ \\ 1 Department of Microbiology, Cornell University, Ithaca, NY 14853, USA; jc2568@cornell.edu \\ 2 Microbial Sciences Institute, Department of Microbial Pathogenesis, Yale University, \\ West Haven, CT 06516, USA; jliu@yale.edu \\ 3 Department of Microbiology, University of Georgia, Athens, GA 30602, USA \\ * Correspondence: trhoover@uga.edu; Tel.: +1-706-542-2675
}

Received: 30 January 2020; Accepted: 26 February 2020; Published: 27 February 2020

check for updates

\begin{abstract}
A number of Gram-negative bacteria have a membrane surrounding their flagella, referred to as the flagellar sheath, which is continuous with the outer membrane. The flagellar sheath was initially described in Vibrio metschnikovii in the early 1950s as an extension of the outer cell wall layer that completely surrounded the flagellar filament. Subsequent studies identified other bacteria that possess flagellar sheaths, most of which are restricted to a few genera of the phylum Proteobacteria. Biochemical analysis of the flagellar sheaths from a few bacterial species revealed the presence of lipopolysaccharide, phospholipids, and outer membrane proteins in the sheath. Some proteins localize preferentially to the flagellar sheath, indicating mechanisms exist for protein partitioning to the sheath. Recent cryo-electron tomography studies have yielded high resolution images of the flagellar sheath and other structures closely associated with the sheath, which has generated insights and new hypotheses for how the flagellar sheath is synthesized. Various functions have been proposed for the flagellar sheath, including preventing disassociation of the flagellin subunits in the presence of gastric acid, avoiding activation of the host innate immune response by flagellin, activating the host immune response, adherence to host cells, and protecting the bacterium from bacteriophages.
\end{abstract}

Keywords: flagellum; flagellar sheath; Helicobacter; Vibrio; cardiolipin

\section{Introduction}

The bacterial flagellum is a complex organelle used for motility and is organized into three basic structures referred to as the basal body, hook and filament. Of these structures, the filament is the most prominent, forming a thin, helical structure that is typically $5-10 \mu \mathrm{m}$ in length and is several times longer than the body of the bacterial cell. The filament is composed of tens of thousands of copies of a single flagellin protein or of multiple closely related flagellin proteins that self-assemble to form a hollow, tubular structure. In most bacterial species, the flagellar filament is exposed directly to the surrounding medium. The filament in several genera of Gram-negative bacteria, however, is surrounded by a membranous sheath that is contiguous with the outer membrane. Flagella in these bacteria are located almost exclusively at the cell pole, and occur as a single flagellum at one cell pole (polar flagellum), as a single flagellum at each cell pole (amphitrichous or bipolar flagella) or as multiple flagella at one cell pole (lophotrichous flagella). In bacteria with a lophotrichous arrangement of flagella, each flagellum is enclosed within a separate sheath. Other types of flagellar sheaths have been described, such as one found in the marine magnetotactic bacterium MO-1, which has a flagellar sheath composed of glycoprotein [1]. The MO-1 flagellar sheath differs further from membranous flagellar sheaths in that it surrounds a flagellar bundle consisting of multiple flagella rather than surrounding each flagellum [1]. Spirochetes enclose their flagella within the periplasmic space, which 
is somewhat analogous to the flagellar sheath in that the flagella of spirochetes are separated from the surrounding medium by a membrane. For additional information on the periplasmic flagella of spirochetes, we refer the reader to a recent review by Wolgemuth [2]. For the purposes of our review, we focus on bacteria that possess membranous flagellar sheaths. It has been nearly four decades since the last comprehensive review of the bacterial flagellar sheath [3], which was a major impetus for this review.

\section{Phylogenetic Distribution of Flagellar Sheaths}

Accurately assessing how widely distributed flagellar sheaths are among bacterial species is not a trivial task since reports on novel species often fail to indicate the presence or absence of a flagellar sheath. Moreover, when reports of novel bacterial species do indicate the presence of a flagellar sheath, they often omit a description of the ultrastructure of the sheath or do not include electron micrographs that clearly show the ultrastructure of the sheath. With these caveats in mind, membranous flagellar sheaths are found primarily in a handful of genera that are scattered throughout the phylum Proteobacteria. Within the Proteobacteria, representatives from five classes (Alphaproteobacteria, Betaproteobacteria, Gammaproteobacteria, Deltaproteobacteria and Epsilonproteobacteria) are reported to possess a membranous flagellar sheath. In addition to the Proteobacteria, some members of the phylum Planctomyces appear to have membranous flagellar sheaths, including Pirella marina and several members of the genus Planctomycetes [4,5].

Members of Alphaproteobacteria that have flagellar sheaths include Seliberia stellate, Azospirillum brasilense, Rhodospirillum centenum, and Brucella melitensis, all of which possess a single polar flagellum [6-9]. Within the Betaproteobacteria, the soil bacterium and plant pathogen Robbsia andropogonis (formerly known as Burkholderia andropogonis, Pseudomonas andropogonis, Pseudomonas stizolobii, as well as other names) has a single polar sheathed flagellum [10]. Busse and Auling indicate that members of the genus Achromobacter, which belong to the class Betaproteobacteria, have a peritrichous arrangement of sheathed flagella [11]. They do not report whether the Achromobacter flagellar sheaths are membranous, although the ultrastructure of Achromobacter xylosoxidans flagella appears consistent with that of a membranous flagellar sheath [12]. If the flagella of Achromobacter are indeed surrounded by a membranous sheath, this would be the only example of a bacterium with peritrichous sheathed flagella of which we are aware. Members of Gammaproteobacteria that have flagellar sheaths include Halorhodospira adbelmalekii [13], several species of Pseudoalteromonas [14-17], and most or all Vibrio species [18]. All of these members of Gammaproteobacteria possess either a single or multiple polar flagella that they use for swimming. In addition to producing a polar sheathed flagellum for swimming, various marine Vibrio species, including Vibrio parahaemolyticus, Vibrio alginolyticus, Vibrio harveyi, and Vibrio shilonii, elaborate lateral flagella that are used for rapid movement on surfaces [19-21]. The lateral flagella of the marine Vibrio species, as well as those of $A$. brasilense and R. centenum, lack a sheath [8,19-22], indicating that sheath biosynthesis is not inherently linked with flagellum biogenesis in these bacteria. Bdellovibrio bacteriovorus, Bacteriovorax stolpii, and Bacteriovorax starrii, which are predators of other Gram-negative bacteria, are members of the class Deltaproteobacteria that possess a single polar sheathed flagellum [23-25]. Within the class Epsilonproteobacteria, only members of the genus Helicobacter are reported to have flagellar sheaths. Most Helicobacter species possess a single sheathed polar flagellum or bipolar sheathed flagella; although the most extensively studied species, Helicobacter pylori, has lophotrichous sheathed flagella, and several Helicobacter species have unsheathed polar flagella. Interestingly, Helicobacter species that possess flagellar sheaths and Helicobacter species that have unsheathed flagella appear to segregate into distinct phylogenetic groups [26].

\section{Composition of Flagellar Sheaths}

Early ultrastructural studies of flagellar sheaths from various bacteria revealed two electron dense layers separated by a region of less electron density, consistent with the flagellar sheath being a unit 
membrane [3]. For some bacteria, including B. bacteriovorus, B. melitensis, H. pylori, and V. fischeri, a bulb-like structure is typically observed at the distal end of the flagellar sheath [7,27-29]. The detailed electron micrographs from the early studies suggested the flagellar sheath was contiguous with the outer membrane, and recent cryo-electron tomography (cryo-ET) studies of sheathed flagella from various bacteria have yielded detailed images that confirm the structural continuity between the outer membrane and flagellar sheath [30-34]. Figure 1 shows tomograms of $V$. cholerae and $H$. pylori sheathed flagella (authors' data).

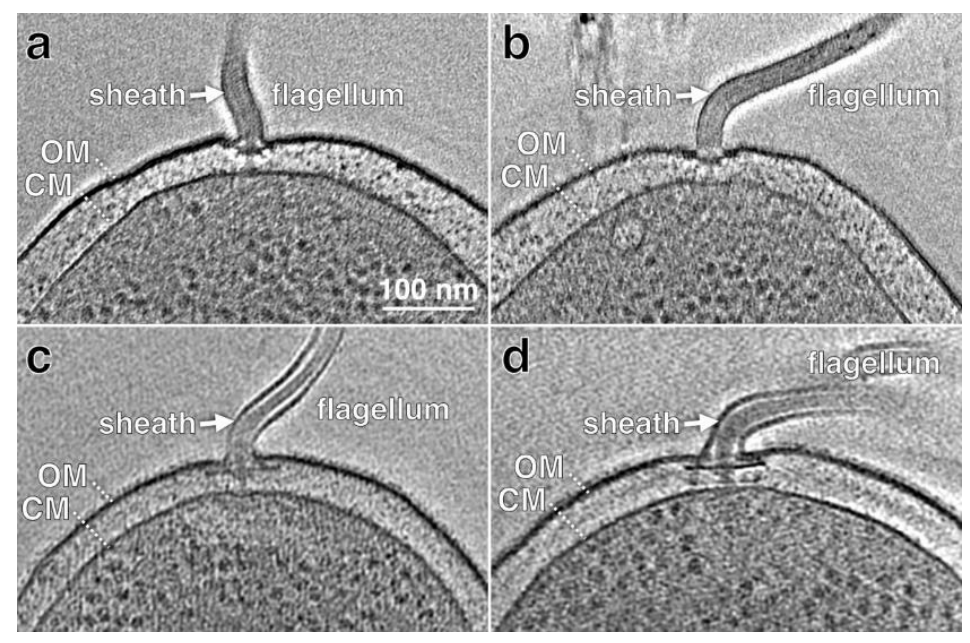

Figure 1. Cryot-ET reconstructions of intact cells show sheathed flagella. (a,b) Two representative sections from cryo-ET reconstructions of $V$. cholerae cells. (c,d) Two representative sections from cryo-ET reconstructions of $H$. pylori cells. The arrows indicate the flagellar sheath. For each flagellum, note the central core that consists of the hook and filament. The outer (OM) and cytoplasmic membranes (CM) are indicated.

Early studies on the flagellar sheath sought to determine if the composition of the sheath was similar to that of the outer membrane by using antibodies directed against lipopolysaccharide (LPS) or other surface antigens in the outer membrane. Hranitzky and co-workers reported for V. cholerae that antibodies directed against a crude flagellar sheath preparation reacted strongly with a component in both the sheath and surface of the cell body [35]. Conversely, Yang and co-workers found that antibodies directed against a purified antigen from the cell body of $V$. cholerae cross-reacted with and immobilized the flagellum [36]. Although Hranitzky and co-workers reported that antibodies directed against $V$. cholerae LPS did not bind to the flagellar sheath [35], a subsequent study with $V$. cholerae found that anti-LPS did indeed recognize the flagellar sheath [37]. While these studies indicated that at least some components are shared between the outer membrane and flagellar sheath, determining whether specific macromolecules localize to the flagellar sheath required further biochemical characterization of isolated flagellar sheaths.

Little information is available on the lipid composition of the flagellar sheath for any bacterium, but the data that are available are intriguing. Thomashow and Rittenberg reported that the LPS of the flagellar sheath of B. bacteriovorous was moderately enriched ( 2.7-fold) for the fatty acid nonadecenoic acid $\left(\mathrm{C}_{19: 1}\right)$ and depleted greatly ( 17-fold) in $\beta$-hydroxymyristic acid (3-OH $\left.\mathrm{C}_{14: 0}\right)$ compared to LPS from bdellovibrios grown on Escherichia coli as a host [29]. This observation indicates $B$. bacteriovorous partitions specific LPS species into the flagellar sheath that differ from those in the outer membrane. Interestingly, the total LPS (i.e., LPS from both the outer membrane and flagellar sheath) from bdellovibrios grown axenically (i.e., on medium instead of host cells) was similar to the flagellar sheath LPS in that it was enriched for nonadecenoic acid and depleted for $\beta$-hydroxymyristic acid [29]. Using immunogold labelling, Norqvist and Wolf-Watz identified a surface antigen in the fish pathogen Vibrio anguillarum that localized specifically to the flagellar sheath [38]. The V. anguillarum 
surface antigen was resistant to proteinase $\mathrm{K}$, but sensitive to periodic acid treatment. In addition, the antigen was absent in mutants that had transposon insertions in vir $A$ and virB, which encode enzymes involved in LPS O1 antigen biosynthesis. Collectively, these findings indicate the V. anguillarum surface antigen is LPS [38], and further suggest that like B. bacteriovorus, V. anguillarum partitions specific LPS species to the flagellar sheath. The mechanisms these bacteria use to segregate specific LPS species to the flagellar sheath are unknown.

In an examination of the fatty acid composition of $H$. pylori flagellar sheaths, Geis and co-workers found there were no fatty acids uniquely associated with the flagellar sheath, but the fatty acid composition profile of the sheath does differ from that of the whole cell membranes [39]. Cardiolipin is a phospholipid that accumulates in regions of membranes that have negative curvature, such as the cell pole and septal regions in rod-shaped bacteria [40-43]. Given the propensity of cardiolipin to accumulate in membranes with negative curvature, one might expect the flagellar sheath to contain significant amounts of cardiolipin. Consistent with this hypothesis, the H. pylori flagellar sheath appears to contain high amounts of cardiolipin [44]. In further support of the hypothesis, the two most abundant fatty acids in $H$. pylori flagellar sheaths, myristic acid $\left(C_{14: 0}\right)$ and cyclopropane nonadecanoic acid $\left(C_{19: 0}\right.$ cyc) [39], are also the two most common fatty acids in cardiolipin species from H. pylori [45-47].

A number of studies have investigated the proteins associated with bacterial flagellar sheaths, although the information on flagellar sheath proteins is still scant. Knowledge of the proteins that localize to the flagellar sheath is critical for understanding the function of the sheath. Early studies on characterizing flagellar sheath proteins relied on serological approaches or SDS-polyacrylamide gel electrophoresis to identify proteins that appeared to be enriched in the flagellar sheath $[29,35,39,48-51]$. These studies typically reported the sizes of the putative flagellar sheath proteins, but did not identify or further characterize the proteins. The B. bacteriovorus flagellar sheath was reported to have substantially less total protein $(23 \%-28 \%$ dry weight) than that of outer membranes from other bacteria, which typically ranges from 40 to $70 \%$ [29]. Using monoclonal antibodies to an outer membrane fraction from H. pylori NCTC 11637, Doig and Trust identified six protein antigens that either localized within or were associated with the outer membrane, but did not recognize the flagellar sheath, which suggested the proteomes of the outer membrane and flagellar sheath of H. pylori differ from each other [48]. Bari and co-workers identified three outer membrane proteins associated with the $V$. cholerae flagellum-OmpU and OmpT, which are porins, and VC1894, which is a predicted collagen-binding surface adhesion [52]. Disrupting ompU or ompT in $V$. cholerae resulted in several flagellum-associated defects, including reduced motility, thinner flagella, increased proportion of non-flagellated cells, and increased release of flagellin into the growth medium [52]. These findings suggest OmpU and OmpT help to stabilize the $V$. cholerae flagellar sheath.

An important question is whether there are proteins that localize preferentially to the flagellar sheath. One protein reported to localize specifically to the $H$. pylori flagellar sheath is the $H$. pylori adhesion A (HpaA), although there are conflicting reports on the localization of this protein. HpaA was first described as a hemagglutinin that was shown by immunogold labelling to be located on the cell surface, but was not detectable on the flagellar sheath [53]. A subsequent study indicated HpaA occurred predominantly in the cytoplasmic fraction of Sarkosyl-solubilized cells, with only trace amounts of HpaA in the inner membrane fraction and no detectable HpaA in the outer membrane fraction [54]. Other immunogold labelling studies showed HpaA was specifically localized to the flagellar sheath [51,55]; while a later immunogold labeling study examined localization of HpaA in five $H$. pylori strains and detected $\mathrm{HpaA}$ on both the flagellar sheath and the bacterial surface in all of the strains [56]. The case for HpaA being a flagellar sheath protein is very compelling, and some of the discrepancies between the reports on the surface location of the protein may be attributed to differences in growth phases of the H. pylori cultures, media used for growing the bacteria, strain variability or choice of antibody [55,56].

In a study of $H$. pylori genes predicted to encode proteins secreted by the type $\mathrm{V}$ (autotransporter) pathway, Radin and co-workers found one of these proteins localized specifically to the flagellar 
sheath, which was determined by immunogold electron microscopy and fluorescence microscopy using an antibody to a c-myc tag introduced within the autotransporter [57]. Given the association of the autotransporter with the flagellar sheath, the researchers designated the protein as FaaA (flagellar-associated autotransporter A). Disrupting faaA resulted in reduced motility and a variety of defects in flagellum biosynthesis or stability, which included increased number of non-flagellated cells, reduced number of flagella per cell, increased frequency of broken flagella, and increased proportion of flagella that localized to nonpolar sites [57]. faa $A$ is not part of any of the known flagellar gene regulons in H. pylori [58]. FaaA is synthesized and localized to the cell surface in a H. pylori 26695 strain that does not produce flagella [59]. Taken together, these findings suggest a role for FaaA in assembly of the flagellum and/or flagellar sheath, but expression of $f a a A$ is not tightly coupled with the expression of flagellar genes.

The physiological role of FaaA is not known, although it is required for optimal colonization in a mouse animal model by $H$. pylori during early stages of infection [57]. The colonization deficiency of the faa $\mathrm{A}$ mutant may result from the defects in motility and flagellum biosynthesis since H. pylori must be motile to penetrate the gastric mucus layer to colonize the gastric mucosa [60]. Proteins secreted by the autotransporter pathway have two domains, a secreted passenger domain and a $\beta$-barrel domain that inserts in the outer membrane and facilitates transport of the passenger domain across the outer membrane [61]. Passenger domains participate in a variety of cellular functions, including enzymatic activities (e.g., proteases, lipases/esterases), contact-dependent growth inhibition, immune evasion, cytotoxicity, cyto-/hemolysis, adherence, biofilm formation, auto-agglutination, and activation of actin polymerases for intracellular motility [61]. Depending on the autotransporter, the passenger domain is cleaved and released outside the cell after it is transported across the outer membrane or it remains linked to the $\beta$-barrel domain and is exposed on the cell surface. Since the c-myc tag used to examine the localization of FaaA was introduced into the passenger domain [57], FaaA belongs to this later class of autotransporters.

\section{Rotation of the Sheathed Flagellum}

Researchers who initially studied flagellar sheaths raised questions about how to apply the rotary model for the bacterial flagellum mechanism. Fuerst proposed two models for how the flagellar filament and sheath cooperated in motility [62]. The first model proposed the filament and sheath rotate together. This model requires the flagellar sheath to be rigid and the intersection of the base of the flagellar sheath and outer membrane to be discontinuous and fluid to enable the sheath to rotate with the filament. The sheath would also interact with the filament, perhaps through hydrophobic interactions, to generate a rigid membrane structure. In the second model, which makes fewer assumptions about the nature of the outer membrane and is seemingly more plausible, the filament rotates freely within a flexible wave-propagating sheath [62]. In this second model, the membrane of the flagellar sheath must be flexible enough to allow distortion by the rotational forces induced by the filament, but robust enough to remain associated with the cell body. Fuerst proposed experiments to examine the movement of polystyrene latex beads attached to the flagellar sheath through anti-sheath antibodies as a possible way to distinguish between his two models [62]; however, to the best of our knowledge, there are no reports that address the behavior of the flagellar sheath as the filament rotates.

Rotation of the sheathed flagellum of various Vibrio species is a major source for outer membrane vesicles (OMVs) that are released from the bacterial cell [63,64]. Aschtgen and co-workers demonstrated that the amount of OMVs released is proportional to the number of sheathed flagella per cell [63]. Specifically, the researchers showed that $V$. cholerae, which has a single polar sheathed flagellum, released fewer OMVs than $V$. parahaemolyticus or $V$. fischeri, which have multiple polar sheathed flagella. The researchers also showed that $E$. coli, which has unsheathed peritrichous flagella, released the fewest amount of OMVs, and a non-flagellated E. coli strain released the same amount of OMVs as its parental strain [63]. It is not known how flagellar rotation results in release of OMVs, but it seems likely that they are shed from the flagellar sheath as the flagellum rotates. Membrane blebs have been 
observed at the tip and shaft of Vibrio flagellar sheaths [65,66], and these blebs may be the source of OMVs that are released during rotation of the flagellum [63].

The outer membrane of Gram-negative bacteria is an asymmetrical lipid bilayer with LPS at the outer leaflet and phospholipids at the inner leaflet, and serves as an effective barrier to antibiotics, detergents and other toxic compounds. Exposure of bacterial cells to antimicrobial peptides or metal chelating agents such as EDTA leads to shedding of LPS and allows phospholipids from the inner leaflet to move into the outer leaflet, thereby compromising the outer membrane as a barrier [67]. Loss of LPS and other macromolecules associated with the flagellar sheath as the flagellum rotates could similarly lead to the migration of phospholipids from the inner leaflet to the outer leaflet, which could be deleterious to the bacterium. Consistent with this hypothesis, the B. bacteriovorus flagellar sheath was reported to have a higher proportion of phospholipids than typical outer membranes, and the authors of this study speculated that this might account for the unusual sensitivity of bdellovibrios to detergents [29]. Gram-negative bacteria have mechanisms for removing phospholipids from the outer leaflet of the outer member to maintain lipid asymmetry $[68,69]$. If shedding of sheath material does indeed compromise the flagellar sheath as a barrier, one might expect some bacteria that possess flagellar sheaths to have robust mechanisms for maintaining the lipid asymmetry of the outer membrane and sheath.

\section{Biogenesis of the Flagellar Sheath}

Little is known regarding the biosynthesis of the flagellar sheath in any bacterial species, which makes any attempt to attribute the phylogenetic distribution of the flagellar sheath to horizontal gene transfer or convergent evolution highly speculative. Regardless of the evolutionary history of the flagellar sheath, it likely is not coincidental that almost all bacteria reported to have a flagellar sheath possess polar flagella. The bacterial cell pole has unique physiochemical properties that may have facilitated the evolution of a membranous sheath at this location. For example, the accumulation of cardiolipin at the bacterial cell pole is attributed to its ability to form clusters or microdomains, which exhibit a high intrinsic curvature and therefore have a lower energy when localized to regions of the membrane with negative curvature [70,71]. In addition to forming microdomains, cardiolipin induces other changes in the physical properties of membranes that may be critical for assembly of the flagellar sheath, such as the ability to form nonbilayer structures [72-74] and decreasing lateral interactions within the monolayer leaflet, which lowers the energy needed to stretch membranes [75]. Localization of specific proteins to the cell pole may also contribute to formation of the flagellar sheath. Cardiolipin interacts strongly with many proteins [76] and, in some cases, cardiolipin is required for recruitment of specific proteins to the cell pole [43,77-79]. Additional mechanisms for localizing specific proteins to the cell pole that do not involve cardiolipin exist in rod-shaped bacteria [80], and such mechanisms could also facilitate flagellar sheath biosynthesis.

An important matter regarding flagellar sheath biogenesis is ascertaining the degree to which it is coupled to assembly of the flagellar filament. Richardson and co-workers generated non-motile mutants of $V$. cholerae following transposon mutagenesis, and identified five mutants that produced sheath-like structures that lacked the flagellar core [81]. In the coreless sheath mutants, a sheath-like structure was observed in about half the cells, and in contrast to the wild-type flagellum, the sheath-like structures were located almost always (>99\%) at non-polar sites [81]. The coreless sheaths were elongated like normal sheaths, but in contrast to normal sheaths, the diameters of the coreless sheaths were irregular. These findings suggest that sheath biogenesis and flagellar assembly in $V$. cholerae can be uncoupled. This uncoupling, however, may be strain specific as the researchers were only able to isolate coreless sheath mutants from the classical strain of V. cholerae, and not the El Tor strain [81]. Unfortunately, the genes that were disrupted in the coreless sheath mutants were never identified, which would have provided clues that might explain the molecular basis for the unusual phenotype of these mutants. Ferooz and Letesson reported that in mutants of B. melitensis where fliF (encodes MS-ring protein), flgE (encodes hook protein), fliC (encodes flagellin) or $f t c R$ (encodes flagellar gene master 
regulator) were deleted, coreless sheaths could be observed on some of the cells [7]. These findings are intriguing since the MS-ring is one of the earliest flagellar structures to be assembled, which suggests sheath biogenesis in $B$ melitensis can initiate and proceed in the absence of any flagellar structure.

In contrast to the studies with $V$. cholerae and B. melitensis flagellar mutants $[7,81]$, studies with wild-type $H$. pylori suggest assembly of the flagellum and sheath biogenesis are tightly coupled. In a high-throughput cryo-ET approach, Qin and co-workers visualized over 300 H. pylori flagella, which allowed them to image intermediate structures during flagellum assembly [32]. Figure 2 shows the intermediate structures of the flagellar sheath that are observed during flagellum assembly (author's data). Based on the series of $H$. pylori flagellum assembly intermediates, the growing rod assembly seems to push against the outer membrane and deform it. As the hook is assembled and grows, the outer membrane is deformed further and eventually forms a bubble that surrounds the hook. During filament assembly, the flagellar sheath and filament appear to elongate simultaneously, and the bulb-like structure seen in the mature flagellum is present in the nascent flagellum [32].

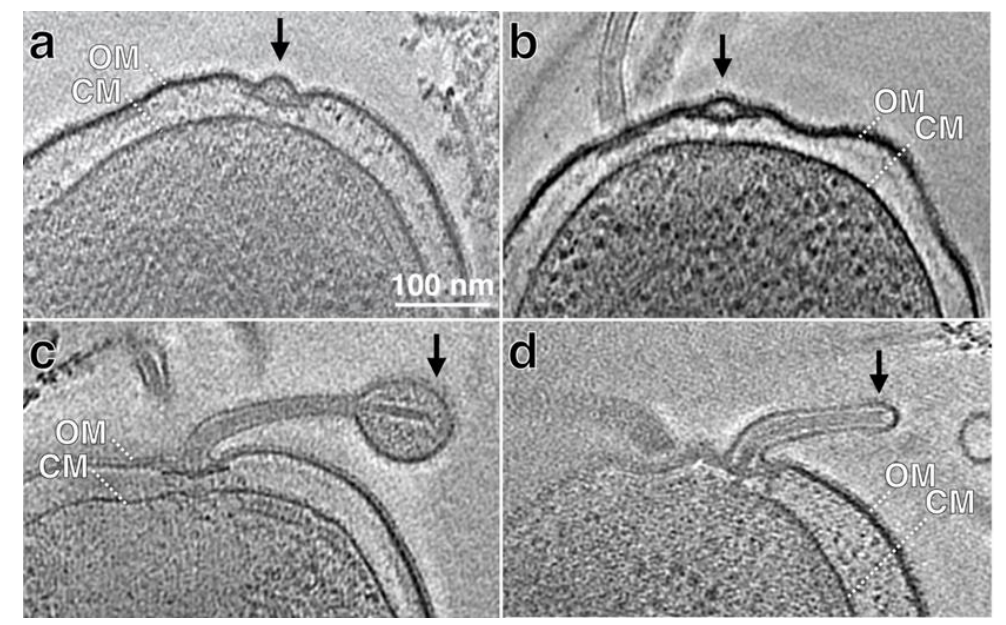

Figure 2. Cryo-ET reconstructions of intact cells show early stages of flagellar assembly and sheath formation. (a,b) Two representative sections from cryo-ET reconstructions of $H$. pylori cells show flagellar basal bodies without hook and filament. (c,d) Two representative sections from cryo-ET reconstructions of $H$. pylori cells show short flagellum. The outer (OM) and cytoplasmic membranes (CM) are indicated.

Virtually nothing is known about proteins that have roles in flagellar sheath biogenesis. The only studies that have shed any light on proteins with potential roles in sheath biosynthesis have been done with $V$. alginolyticus. In a cryo-ET analysis of the V. alginolyticus sheathed flagellum, Zhu and co-workers observed a ring-like structure associated with the base of the flagellar sheath [33]. The structure, designated as the O-ring, was located on the exterior side of the outer membrane, which displayed a striking $90^{\circ}$ bend at the site of the O-ring [33]. The location of the O-ring and apparent deformation in the outer membrane that it elicits suggests a critical role for the O-ring in formation or function of the flagellar sheath. Figure 3 presents a model for assembly of the flagellum and flagellar sheath in $V$. alginolyticus. The genes encoding the O-ring protein(s) have yet to be identified, which has prevented researchers from confirming a role for the O-ring in flagellar sheath biogenesis. Structures that are analogous to the O-ring have not been identified in any other bacteria with sheathed flagella, indicating that any role for the O-ring in flagellar sheath biogenesis in $V$. alginolyticus is not universal among bacteria that possess flagellar sheaths. 

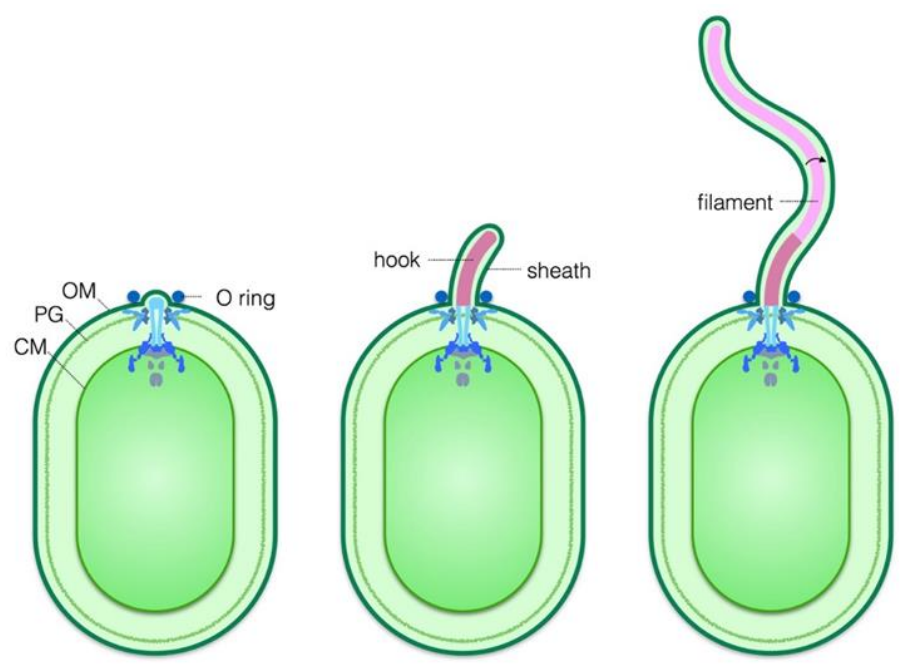

Figure 3. A schematic of assembly and sheath formation of a sheathed flagellum of Vibrio alginolyticus. The O-ring is assembled on the exterior side of the outer membrane at the point where the nascent flagellar sheath emerges. As the hook and filament are assembled, the flagellar sheath extends to encase these structures. The O-ring remains positioned at the base of the flagellar sheath where it stabilizes or induces a sharp bend in the outer membrane as it transitions into the flagellar sheath. The outer (OM), cytoplasmic membranes (CM), and peptidoglycan (PG) are indicated.

The flagellar motors of many bacteria have embellishments that are absent in the archetypical flagellar motors of E. coli and S. enterica serovar Typhimurium [30-33,82]. One such embellishment is the H-ring, which is closely associated with the L-ring/P-ring complex and in close proximity to the outer membrane in Vibrio species [30,33]. The H-ring is located on the periplasmic side of the outer membrane, and the proteins that comprise the H-ring ( $\mathrm{FlgO}$ and $\mathrm{FlgT}$ ) have been identified $[30,83,84]$. $\mathrm{Zhu}$ and co-workers demonstrated that deletion of flgO or $f l g T$ in $V$. alginolyticus disrupted formation of the H-ring and resulted in a many of the flagella being located in the periplasm [84]. About $80 \%$ of the flagella in the $f l g T$ mutant were located in the periplasm, compared with about $10 \%$ of the flagella in the $f \operatorname{lgO}$ mutant and none of the flagella in the parental strain having a periplasmic location [84]. Some of the filaments of the periplasmic flagella protruded through the outer membrane at sites that were far from the cell pole. Some of the protruding filaments were encased in a flagellar sheath, while others lacked a sheath [84]. Taken together, these observations suggest the H-ring assists the flagellum in penetrating the outer membrane and forming the flagellar sheath.

\section{Proposed Functions for Flagellar Sheaths}

A variety of functions have been proposed for bacterial flagellar sheaths, however, the lack of sheath-less mutants for any bacterial species makes it difficult to confirm proposed functions for the flagellar sheath. The flagellar sheath may have multiple functions within a given bacterial species, and functions of the sheath may vary between species. For H. pylori, one of the original proposed functions for the flagellar sheath was to protect the filament subunits from dissociation in the presence of gastric acid. The H. pylori flagellar sheath has also been proposed to be involved in adherence. In support of the proposed role of the $H$. pylori flagellar sheath in adherence, the putative adhesion HpaA is reported to be located in the flagellar sheath. While HpaA was originally described as a sialic acid binding adhesion [53,85], supporting evidence for this activity is still lacking [54,55], and so it is unclear if HpaA does indeed have a role in adherence. Nevertheless, HpaA is required for colonization of the mouse model [86].

Another proposed function for the flagellar sheath is escaping detection of the flagellins by the host innate immune system. Toll-like receptor 5 (TLR5) is a surface exposed host receptor that recognizes flagellin [87]. Binding of flagellin to TLR5 stimulates proinflammatory cytokine production, which 
induces an inflammatory response that can lead to active clearance of the invading bacterium and an enhancement of the adaptive immune response [88]. Yoon and Mekalanos demonstrated that compared to the unsheathed flagella of Salmonella enterica serovar Typhimurium, the sheathed flagella of $V$. cholerae were significantly reduced in their relative potency to trigger the host innate response [89]. The $V$. cholerae flagellins and $S$. enterica serovar Typhimurium flagellin were similar in their potencies to trigger the host innate response, indicating that the $V$. cholerae flagellar sheath is effective in hiding immunogenic flagellins [89]. TLR5 recognizes a highly conserved region of flagellin that is required for flagellum assembly in members of the Gammaproteobacteria [90]. Flagellins of H. pylori and other members of the Epsilonproteobacteria lack the conserved region that interacts with TLR5 [91], which suggests the flagellar sheath does not play a major role in avoiding triggering the host innate immune response by flagellin in these bacteria.

The flagellins of several bacterial species are glycosylated (i.e., post-translationally modified by the covalent attachment of carbohydrates to specific amino acids), and some of these bacteria possess flagellar sheaths [92,93]. Flagellar glycans have roles in a variety of processes, including flagellar filament assembly, motility, autoaggultination, adherence to and invasion of host cells, virulence, and evasion of the host innate immune system [94-100]. H. pylori flagellins FlaA and FlaB are modified with a single type of glycan, pseudaminic acid, and flagellin glycosylation is required for assembly of the flagellar filament [100]. Flagellin glycosylation in Campylobacter jejuni, which is closely related to $H$. pylori, is also required for filament assembly, but the glycans of the C. jejuni flagellins are much more heterogeneous, and include various derivatives of pseudaminic acid and a derivative of legionaminic acid [101,102]. Logan proposed that the H. pylori flagellar sheath prevents recognition of the flagellin glycan by the host immune system, which may have decreased the evolutionary pressure for glycan heterogeneity in this bacterium [92].

As discussed previously, rotation of the sheathed flagellum of Vibrio species releases OMVs, which are known to have important roles in host signaling in symbiosis and pathogenesis. In the symbiosis between $V$. fischeri and the Hawaiian bobtail squid, Euprymna scolopes, LPS associated with the OMVs induces apoptotic cell death within the surface epithelium of the squid light organ that is required for its normal development $[63,64]$. Vanhove and co-workers found that OMVs released from $V$. tasmaniensis, a facultative intracellular pathogen of oyster haemocytes, contained several virulence factors that could be delivered to host cells either extracellularly or intracellularly [66]. The presence of several flagellar proteins in the OMVs and the occurrence of membrane blebs on flagellar sheaths suggested that some of the OMVs originated from the flagellar sheath [66]. It is not known, however, if OMVs derived from the flagellar sheath contain virulence factors.

OMVs also have a potential role in innate bacterial defense, as Manning and Kuehn showed OMVs protected enterotoxigenic E. coli from certain outer membrane-acting stressors, such as antimicrobial peptides and T4 bacteriophage [103]. OMVs interacted with antimicrobial peptides in a dose-dependent manner; and irreversibly bound phage, as well as reduced the ability of phage to infect once attached to the OMV [103]. In a somewhat related study, Zhang and co-workers demonstrated that rotation of the polar sheathed flagellum reduced absorption of phage OWB to V. parahaemolyticus [104]. Mutations that prevented either the synthesis or rotation of the polar flagellum enhanced the ability of the phage to lyse the bacterium [104]. The authors of this study suggested rotation of the sheathed flagellum of $V$. parahaemolyticus protects the bacterium from phage by releasing OMVs that bound the phage [104]. Alternatively, rotation of the polar flagellum is a mechanosensory mechanism that regulates gene expression [105], and mutations that prevent rotation of the polar flagellum may alter the cell surface to enhance phage absorption.

Another potential function of flagellar sheaths is to protect bacteria from flagellotropic phages, a group of phages that use the flagellar filament as a host receptor for attachment. The infection mechanism of flagellotropic phages is poorly understood, but flagellar rotation is required for infection and is thought to facilitate translocation of the phage along the filament to the cell surface [106]. It is possible flagellar sheaths evolved as a mechanism to hide the flagellar filament from flagellotropic 
phages. Consistent with this hypothesis, we are unaware of any reports on flagellotropic phages of bacteria that possess flagellar sheaths; although flagellotropic phages of bacterial species closely related to bacteria that have flagellar sheaths have been reported, such as phage F342 of C. jejuni [107].

\section{Conclusions and Future Directions}

The 1983 review of bacterial flagellar sheaths by Sjoblad and colleagues begins with the statement, "Although bacterial flagellar sheaths were observed over 30 years ago, they may still be characterized as structures in search of a function" [3]. Some of the assumed roles for flagellar sheaths in 1983, such as adherence, are still considered as possible roles for flagellar sheaths today. And although additional roles have been postulated for bacterial flagellar sheaths over the last 37 years, limitations in our knowledge of flagellar sheath biosynthesis and the lack of mutants that synthesize sheath-less flagella thwart efforts to confirm proposed functions for flagellar sheaths.

The limited number of studies that have examined the composition of flagellar sheaths have indicted the sheath is both similar to and different from the outer membrane. Differences in the LPS composition of flagellar sheaths and the outer membrane indicated by some studies $[29,38]$ require an unknown mechanism to segregate specific LPS species within what appears to otherwise be a contiguous membrane. Mechanisms for localizing specific proteins to the sheath are easier to envision. For example, bacterial proteins are localized to the cell pole through a diffusion-capture mechanism in which proteins are inserted into the membrane where they can diffuse until encountering a geometrical cue (e.g., membrane curvature) or biochemical cue (e.g., specific phospholipids or other proteins already localized to the site) [80]. Given the unique physiochemical properties of flagellar sheaths (e.g., shape, phospholipid composition), such a diffusion-capture mechanism is likely to be responsible for the localization of proteins to the flagellar sheath. Studies in V. cholerae and H. pylori have identified proteins that appear to localize to the flagellar sheath [51,52,55,57], and future studies in these bacteria, as well as other bacterial species, will most certainly lead to the identification of additional flagellar sheath proteins. Dissecting the lipid and protein composition of bacterial flagellar sheaths is critical for understanding the function and biogenesis of these unique structures.

One of the most fascinating areas for future investigations into flagellar sheaths is understanding how these structures are assembled. Making headway in understanding the molecular mechanisms that control flagellar sheath biogenesis will require a combination of genetic, biochemical, and structural approaches. High-throughput cryo-ET studies, like that done by Qin and co-workers with H. pylori [32], will need to be done with other bacterial species. Identifying and disrupting genes that encode structural features intimately associated with flagellar sheaths, such as the O-ring of V. alginolyticus, will be required to ascertain the roles these genes play in flagellar sheath biosynthesis. Creative genetic screens will be needed to identify genes that are required for flagellar sheath biosynthesis and, hopefully, lead to the generation of mutant strains that produce sheath-less flagella, which can be used to test the requirement of the flagellar sheath in host colonization and pathogenesis. Biochemical studies will be needed to examine the composition of flagellar sheaths, as well as confirm the predicted activities of the products of candidate genes for sheath biosynthesis identified through genetic and genomic approaches.

Author Contributions: Conceptualization, J.C. and T.R.H.; writing-original draft preparation, J.C.; writing-review and editing, T.R.H.; visualization, J.L.; funding acquisition, T.R.H. and J.L. All authors have read and agreed to the published version of the manuscript.

Funding: This research was funded by NIH grant AI140444 to T.H., and NIH grants GM107629 and AI087946 to J.L.

Acknowledgments: We thank Katherine Gibson and Anna Karls for their thoughtful feedback on the manuscript. Conflicts of Interest: The authors declare no conflict of interest. 


\section{References}

1. Lefevre, C.T.; Santini, C.L.; Bernadac, A.; Zhang, W.J.; Li, Y.; Wu, L.F. Calcium ion-mediated assembly and function of glycosylated flagellar sheath of marine magnetotactic bacterium. Mol. Microbiol 2010, 78, 1304-1312. [CrossRef] [PubMed]

2. Wolgemuth, C.W. Flagellar motility of the pathogenic spirochetes. Semin Cell Dev. Biol. 2015, 46, 104-112. [CrossRef] [PubMed]

3. Sjoblad, R.D.; Emala, C.W.; Doetsch, R.N. Invited review: Bacterial flagellar sheaths: Structures in search of a function. Cell Motil. 1983, 3, 93-103. [CrossRef] [PubMed]

4. Fuerst, J.A. The planctomycetes: Emerging models for microbial ecology, evolution and cell biology. Microbiology 1995, 141, 1493-1506. [CrossRef] [PubMed]

5. Schlesner, H. Pirella marina sp. nov., a budding, peptidoglycan-less bacterium from brackish water. Syst. Appl. Microbiol. 1986, 8, 177-180. [CrossRef]

6. Burygin, G.L.; Shirokov, A.A.; Shelud'ko, A.V.; Katsy, E.I.; Shchygolev, S.Y.; Matora, L.Y. Detection of a sheath on Azospirillum brasilense polar flagellum. Microbiology 2007, 76, 728-734. [CrossRef]

7. Ferooz, J.; Letesson, J.J. Morphological analysis of the sheathed flagellum of Brucella melitensis. BMC Res. Notes 2010, 3, 333. [CrossRef]

8. Ragatz, L.; Jiang, Z.Y.; Bauer, C.E.; Gest, H. Macroscopic phototactic behavior of the purple photosynthetic bacterium Rhodospirillum centenum. Arch. Microbiol. 1995, 163, 1-6. [CrossRef]

9. Schmidt, J.M.; Starr, M.P. Unidirectional polar growth of cells of Seliberia stellata and aquatic seliberia-like bacteria revealed by immunoferritin labeling. Arch. Microbiol. 1984, 138, 89-95. [CrossRef]

10. Fuerst, J.A.; Hayward, A.C. The sheathed flagellum of Pseudomonas stizolobii. J. Gen. Microbiol. 1969, 58, 239-245. [CrossRef]

11. Busse, H.-J.; Auling, G. Achromobacter. In Bergy's Manual of Systematics of Archaea and Bacteria; Whitman, W., Rainey, F., Kampfer, P., Trujillo, M., Chun, J., DeVos, P., Eds.; John Wiley \& Sons: Hoboken, NJ, USA, 2015.

12. Yabuuchi, E.; Yano, I.; Goto, S.; Tanimura, E.; Ito, T.; Ohyama, A. Description of Achromobacter xylosoxidans Yabuuchi and Ohyama 1971. Int. J. Syst. Bacteriol. 1974, 24, 470-477. [CrossRef]

13. Imhoff, J.F.; Truper, H.G. Ectothiorhodospira abdelmalekii sp. nov., a new halophilic and alkaliphilic phototrophic bacterium. Zbl Bakt Hyg I Abt Orig C 1981, 2, 228-234. [CrossRef]

14. Enger, O.; Nygaard, H.; Solberg, M.; Schei, G.; Nielsen, J.; Dundas, I. Characterization of Alteromonas denitrificans sp. nov. Int. J. Syst. Bacteriol. 1987, 37, 416-421. [CrossRef]

15. Hansen, A.J.; Ingebritsen, A.; Weeks, O.B. Flagellation of Flavabacterium piscicida. J. Bacteriol. 1963, 86, 602-603. [CrossRef] [PubMed]

16. Holmstrom, C.; James, S.; Neilan, B.A.; White, D.C.; Kjelleberg, S. Pseudoalteromonas tunicata sp. nov., a bacterium that produces antifouling agents. Int. J. Syst. Bacteriol. 1998, 48, 1205-1212. [CrossRef] [PubMed]

17. Novick, J.J.; Tyler, M.E. Isolation and characterization of Alteromonas luteoviolacea strains with sheathed flagella. Int. J. Syst. Bacteriol. 1985, 35, 111-113. [CrossRef]

18. Farmer, J.J., III; Janda, J.M.; Brenner, F.W.; Cameron, D.N.; Birkhead, K.M. Genus I. Vibrio Pacini 1854, 411AL. In Bergey's Manual of Systematic Bacteriology, 2nd ed.; Brenner, D.J., Krieg, N.R., Staley, J.R., Garrity, G., Eds.; Springer: New York, NY, USA, 2005; Volume 2, Part B; pp. 494-546.

19. Gonzalez, Y.; Venegas, D.; Mendoza-Hernandez, G.; Camarena, L.; Dreyfus, G. $\mathrm{Na}^{+}$- and $\mathrm{H}^{+}$-dependent motility in the coral pathogen Vibrio shilonii. Fems. Microbiol. Lett. 2010, 312, 142-150. [CrossRef]

20. McCarter, L.L. Polar flagellar motility of the Vibrionaceae. Microbiol. Mol. Biol. Rev. 2001, 65, 445-462, table of contents. [CrossRef]

21. McCarter, L.L. Dual flagellar systems enable motility under different circumstances. J. Mol. Microbiol. Biotechnol 2004, 7, 18-29. [CrossRef]

22. Tarrand, J.J.; Krieg, N.R.; Dobereiner, J. A taxonomic study of the Spirillum lipoferum group, with descriptions of a new genus, Azospirillum gen. nov. and two species, Azospirillum lipoferum (Beijerinck) comb. nov. and Azospirillum brasilense sp. nov. Can. J. Microbiol. 1978, 24, 967-980. [CrossRef]

23. Burnham, J.C.; Hashimoto, T.; Conti, S.F. Electron microscopic observations on the penetration of Bdellovibrio bacteriovorus into gram-negative bacterial hosts. J. Bacteriol. 1968, 96, 1366-1381. [CrossRef] [PubMed]

24. Seidler, R.J.; Starr, M.P. Structure of the flagellum of Bdellovibrio bacteriovorus. J. Bacteriol. 1968, 95, $1952-1955$. [CrossRef] [PubMed] 
25. Williams, H.; Baer, M. Genus II. Bacteriovorax Baer, Ravel, Chun, Hill and Williams 2000, 222VP. In Bergey's Manual of Systematic Bacteriology, 2nd ed.; Brenner, D.J., Krieg, N.R., Staley, J.R., Garrity, G., Eds.; Springer: New York, NY, USA, 2005; Volume 2, Part C; pp. 1053-1057.

26. Berthenet, E.; Benejat, L.; Menard, A.; Varon, C.; Lacomme, S.; Gontier, E.; Raymond, J.; Boussaba, O.; Toulza, O.; Ducournau, A.; et al. Whole-genome sequencing and bioinformatics as pertinent tools to support Helicobacteracae taxonomy, based on three strains suspected to belong to novel Helicobacter species. Front. Microbiol. 2019, 10, 2820. [CrossRef] [PubMed]

27. Allen, R.D.; Baumann, P. Structure and arrangement of flagella in species of the genus Beneckea and Photobacterium fischeri. J. Bacteriol. 1971, 107, 295-302. [CrossRef] [PubMed]

28. Geis, G.; Leying, H.; Suerbaum, S.; Mai, U.; Opferkuch, W. Ultrastructure and chemical analysis of Campylobacter pylori flagella. J. Clin. Microbiol. 1989, 27, 436-441. [CrossRef]

29. Thomashow, L.S.; Rittenberg, S.C. Isolation and composition of sheathed flagella from Bdellovibrio bacteriovorus 109J. J. Bacteriol. 1985, 163, 1047-1054. [CrossRef]

30. Beeby, M.; Ribardo, D.A.; Brennan, C.A.; Ruby, E.G.; Jensen, G.J.; Hendrixson, D.R. Diverse high-torque bacterial flagellar motors assemble wider stator rings using a conserved protein scaffold. Proc. Natl. Acad. Sci. USA 2016, 113, E1917-E1926. [CrossRef]

31. Chen, S.; Beeby, M.; Murphy, G.E.; Leadbetter, J.R.; Hendrixson, D.R.; Briegel, A.; Li, Z.; Shi, J.; Tocheva, E.I.; Muller, A.; et al. Structural diversity of bacterial flagellar motors. EMBO J. 2011, 30, 2972-2981. [CrossRef]

32. Qin, Z.; Lin, W.T.; Zhu, S.; Franco, A.T.; Liu, J. Imaging the motility and chemotaxis machineries in Helicobacter pylori by cryo-electron tomography. J. Bacteriol. 2017, 199, e00695-16. [CrossRef]

33. Zhu, S.; Nishikino, T.; Hu, B.; Kojima, S.; Homma, M.; Liu, J. Molecular architecture of the sheathed polar flagellum in Vibrio alginolyticus. Proc. Natl. Acad. Sci. USA 2017, 114, 10966-10971. [CrossRef]

34. Zhu, S.; Nishikino, T.; Takekawa, N.; Terashima, H.; Kojima, S.; Imada, K.; Homma, M.; Liu, J. In situ structure of the Vibrio polar flagellum reveals distinct outer membrane complex and its specific interaction with the stator. J. Bacteriol. 2019. [CrossRef] [PubMed]

35. Hranitzky, K.W.; Mulholland, A.; Larson, A.D.; Eubanks, E.R.; Hart, L.T. Characterization of a flagellar sheath protein of Vibrio cholerae. Infect. Immun. 1980, 27, 597-603. [CrossRef] [PubMed]

36. Yang, G.C.; Schrank, G.D.; Freeman, B.A. Purification of flagellar cores of Vibrio cholerae. J. Bacteriol. 1977, 129, 1121-1128. [CrossRef] [PubMed]

37. Fuerst, J.A.; Perry, J.W. Demonstration of lipopolysaccharide on sheathed flagella of Vibrio cholerae O:1 by protein A-gold immunoelectron microscopy. J. Bacteriol. 1988, 170, 1488-1494. [CrossRef]

38. Norqvist, A.; Wolf-Watz, H. Characterization of a novel chromosomal virulence locus involved in expression of a major surface flagellar sheath antigen of the fish pathogen Vibrio anguillarum. Infect. Immun. 1993, 61, 2434-2444. [CrossRef]

39. Geis, G.; Suerbaum, S.; Forsthoff, B.; Leying, H.; Opferkuch, W. Ultrastructure and biochemical studies of the flagellar sheath of Helicobacter pylori. J. Med. Microbiol. 1993, 38, 371-377. [CrossRef]

40. Bernal, P.; Munoz-Rojas, J.; Hurtado, A.; Ramos, J.L.; Segura, A. A Pseudomonas putida cardiolipin synthesis mutant exhibits increased sensitivity to drugs related to transport functionality. Environ. Microbiol. 2007, 9, 1135-1145. [CrossRef]

41. Kawai, F.; Shoda, M.; Harashima, R.; Sadaie, Y.; Hara, H.; Matsumoto, K. Cardiolipin domains in Bacillus subtilis Marburg membranes. J. Bacteriol. 2004, 186, 1475-1483. [CrossRef]

42. Mileykovskaya, E.; Dowhan, W. Visualization of phospholipid domains in Escherichia coli by using the cardiolipin-specific fluorescent dye 10-N-nonyl acridine orange. J. Bacteriol. 2000, 182, 1172-1175. [CrossRef]

43. Romantsov, T.; Helbig, S.; Culham, D.E.; Gill, C.; Stalker, L.; Wood, J.M. Cardiolipin promotes polar localization of osmosensory transporter ProP in Escherichia coli. Mol. Microbiol. 2007, 64, 1455-1465. [CrossRef]

44. Chu, J. Understanding the Role of Cardiolipin in Helicobacter Pylori Flagellar Synthesis. Ph.D. Thesis, University of Georgia, Athens, Georgia, 2019.

45. Chu, J.K.; Zhu, S.; Herrera, C.M.; Henderson, J.C.; Liu, J.; Trent, M.S.; Hoover, T.R. Loss of a cardiolipin synthase in Helicobacter pylori G27 blocks flagellum assembly. J. Bacteriol. 2019, 201. [CrossRef] [PubMed]

46. Hirai, Y.; Haque, M.; Yoshida, T.; Yokota, K.; Yasuda, T.; Oguma, K. Unique cholesteryl glucosides in Helicobacter pylori: Composition and structural analysis. J. Bacteriol. 1995, 177, 5327-5333. [CrossRef] [PubMed] 
47. Zhou, P.; Hu, R.; Chandan, V.; Kuolee, R.; Liu, X.; Chen, W.; Liu, B.; Altman, E.; Li, J. Simultaneous analysis of cardiolipin and lipid A from Helicobacter pylori by matrix-assisted laser desorption/ionization time-of-flight mass spectrometry. Mol. Biosyst 2012, 8, 720-725. [CrossRef]

48. Doig, P.; Trust, T.J. Identification of surface-exposed outer membrane antigens of Helicobacter pylori. Infect. Immun. 1994, 62, 4526-4533. [CrossRef] [PubMed]

49. Furuno, M.; Sato, K.; Kawagishi, I.; Homma, M. Characterization of a flagellar sheath component, PF60, and its structural gene in marine Vibrio. J. Biochem. 2000, 127, 29-36. [CrossRef] [PubMed]

50. Luke, C.J.; Kubiak, E.; Cockayne, A.; Elliott, T.S.; Penn, C.W. Identification of flagellar and associated polypeptides of Helicobacter (formerly Campylobacter) pylori. Fems. Microbiol. Lett. 1990, 59, 225-230. [CrossRef]

51. Luke, C.J.; Penn, C.W. Identification of a $29 \mathrm{kDa}$ flagellar sheath protein in Helicobacter pylori using a murine monoclonal antibody. Microbiology 1995, 141, 597-604. [CrossRef]

52. Bari, W.; Lee, K.M.; Yoon, S.S. Structural and functional importance of outer membrane proteins in Vibrio cholerae flagellum. J. Microbiol. 2012, 50, 631-637. [CrossRef]

53. Evans, D.G.; Evans, D.J., Jr.; Moulds, J.J.; Graham, D.Y. N-acetylneuraminyllactose-binding fibrillar hemagglutinin of Campylobacter pylori: A putative colonization factor antigen. Infect. Immun. 1988, 56, 2896-2906. [CrossRef]

54. O'Toole, P.W.; Janzon, L.; Doig, P.; Huang, J.; Kostrzynska, M.; Trust, T.J. The putative neuraminyllactose-binding hemagglutinin HpaA of Helicobacter pylori CCUG 17874 is a lipoprotein. J. Bacteriol. 1995, 177, 6049-6057. [CrossRef]

55. Jones, A.C.; Logan, R.P.H.; Foynes, S.; Cackayne, A.; Wren, B.W.; Penn, C.W. A flagellar sheath protein of Helicobacter pylori is identical to $\mathrm{HpaA}$, a putative $N$-acetylneuraminyllactose-binding hemagglutinin, but is not an adhesin for AGS cells. J. Bacteriol. 1997, 179, 5643-5647. [CrossRef] [PubMed]

56. Lundstrom, A.M.; Blom, K.; Sundaeus, V.; Bolin, I. HpaA shows variable surface localization but the gene expression is similar in different Helicobacter pylori strains. Microb Pathog 2001, 31, 243-253. [CrossRef] [PubMed]

57. Radin, J.N.; Gaddy, J.A.; Gonzalez-Rivera, C.; Loh, J.T.; Algood, H.M.; Cover, T.L. Flagellar localization of a Helicobacter pylori autotransporter protein. MBio 2013, 4, e00613-12. [CrossRef] [PubMed]

58. Niehus, E.; Gressmann, H.; Ye, F.; Schlapbach, R.; Dehio, M.; Dehio, C.; Stack, A.; Meyer, T.F.; Suerbaum, S.; Josenhans, C. Genome-wide analysis of transcriptional hierarchy and feedback regulation in the flagellar system of Helicobacter pylori. Mol. Microbiol. 2004, 52, 947-961. [CrossRef] [PubMed]

59. Voss, B.J.; Gaddy, J.A.; McDonald, W.H.; Cover, T.L. Analysis of surface-exposed outer membrane proteins in Helicobacter pylori. J. Bacteriol. 2014, 196, 2455-2471. [CrossRef]

60. Ottemann, K.M.; Lowenthal, A.C. Helicobacter pylori uses motility for initial colonization and to attain robust infection. Infect. Immun. 2002, 70, 1984-1990. [CrossRef]

61. Meuskens, I.; Saragliadis, A.; Leo, J.C.; Linke, D. Type V secretion systems: An overview of passenger domain functions. Front. Microbiol. 2019, 10, 1163. [CrossRef]

62. Fuerst, J.A. Bacterial sheathed flagella and the rotary motor model for the mechanism of bacterial motility. J. Biol. 1980, 84, 761-774. [CrossRef]

63. Aschtgen, M.S.; Lynch, J.B.; Koch, E.; Schwartzman, J.; McFall-Ngai, M.; Ruby, E. Rotation of Vibrio fischeri flagella produces outer membrane vesicles that induce host development. J. Bacteriol. 2016, 198, 2156-2165. [CrossRef]

64. Brennan, C.A.; Hunt, J.R.; Kremer, N.; Krasity, B.C.; Apicella, M.A.; McFall-Ngai, M.J.; Ruby, E.G. A model symbiosis reveals a role for sheathed-flagellum rotation in the release of immunogenic lipopolysaccharide. Elife 2014, 3, e01579. [CrossRef]

65. Millikan, D.S.; Ruby, E.G. Vibrio fischeri flagellin A is essential for normal motility and for symbiotic competence during initial squid light organ colonization. J. Bacteriol. 2004, 186, 4315-4325. [CrossRef] [PubMed]

66. Vanhove, A.S.; Duperthuy, M.; Charriere, G.M.; Le Roux, F.; Goudenege, D.; Gourbal, B.; Kieffer-Jaquinod, S.; Coute, Y.; Wai, S.N.; Destoumieux-Garzon, D. Outer membrane vesicles are vehicles for the delivery of Vibrio tasmaniensis virulence factors to oyster immune cells. Environ. Microbiol. 2015, 17, 1152-1165. [CrossRef]

67. Nikaido, H. Molecular basis of bacterial outer membrane permeability revisited. Microbiol Mol. Biol. Rev. 2003, 67, 593-656. [CrossRef] [PubMed] 
68. Dekker, N. Outer-membrane phospholipase A: Known structure, unknown biological function. Mol. Microbiol. 2000, 35, 711-717. [CrossRef] [PubMed]

69. Malinverni, J.C.; Silhavy, T.J. An ABC transport system that maintains lipid asymmetry in the gram-negative outer membrane. Proc. Natl. Acad. Sci. USA 2009, 106, 8009-8014. [CrossRef] [PubMed]

70. Huang, K.C.; Mukhopadhyay, R.; Wingreen, N.S. A curvature-mediated mechanism for localization of lipids to bacterial poles. PLoS Comput. Biol. 2006, 2, e151. [CrossRef] [PubMed]

71. Renner, L.D.; Weibel, D.B. Cardiolipin microdomains localize to negatively curved regions of Escherichia coli membranes. Proc. Natl. Acad. Sci USA 2011, 108, 6264-6269. [CrossRef]

72. Dahlberg, M. Polymorphic phase behavior of cardiolipin derivatives studied by coarse-grained molecular dynamics. J. Phys. Chem. B 2007, 111, 7194-7200. [CrossRef]

73. Schlame, M. Cardiolipin synthesis for the assembly of bacterial and mitochondrial membranes. J. Lipid. Res. 2008, 49, 1607-1620. [CrossRef]

74. Schlame, M.; Rua, D.; Greenberg, M.L. The biosynthesis and functional role of cardiolipin. Prog. Lipid. Res. 2000, 39, 257-288. [CrossRef]

75. Nichols-Smith, S.; Teh, S.Y.; Kuhl, T.L. Thermodynamic and mechanical properties of model mitochondrial membranes. Biochim Biophys. Acta 2004, 1663, 82-88. [CrossRef] [PubMed]

76. Planas-Iglesias, J.; Dwarakanath, H.; Mohammadyani, D.; Yanamala, N.; Kagan, V.E.; Klein-Seetharaman, J. Cardiolipin interactions with proteins. Biophys. J. 2015, 109, 1282-1294. [CrossRef] [PubMed]

77. Buskirk, S.W.; Lafontaine, E.R. Moraxella catarrhalis expresses a cardiolipin synthase that impacts adherence to human epithelial cells. J. Bacteriol. 2014, 196, 107-120. [CrossRef] [PubMed]

78. Romantsov, T.; Gonzalez, K.; Sahtout, N.; Culham, D.E.; Coumoundouros, C.; Garner, J.; Kerr, C.H.; Chang, L.; Turner, R.J.; Wood, J.M. Cardiolipin synthase A colocalizes with cardiolipin and osmosensing transporter ProP at the poles of Escherichia coli cells. Mol. Microbiol. 2018, 107, 623-638. [CrossRef] [PubMed]

79. Rossi, R.M.; Yum, L.; Agaisse, H.; Payne, S.M. Cardiolipin synthesis and outer membrane localization are required for Shigella flexneri virulence. MBio 2017, 8. [CrossRef] [PubMed]

80. Treuner-Lange, A.; Sogaard-Andersen, L. Regulation of cell polarity in bacteria. J. Cell Biol. 2014, $206,7-17$. [CrossRef]

81. Richardson, K.; Nixon, L.; Mostow, P.; Kaper, J.B.; Michalski, J. Transposon-induced non-motile mutants of Vibrio cholerae. J. Gen. Microbiol. 1990, 136, 717-725. [CrossRef]

82. Chaban, B.; Coleman, I.; Beeby, M. Evolution of higher torque in Campylobacter-type bacterial flagellar motors. Sci. Rep. 2018, 8, 97. [CrossRef]

83. Terashima, H.; Koike, M.; Kojima, S.; Homma, M. The flagellar basal body-associated protein FlgT is essential for a novel ring structure in the sodium-driven Vibrio motor. J. Bacteriol. 2010, 192, 5609-5615. [CrossRef]

84. Zhu, S.; Nishikino, T.; Kojima, S.; Homma, M.; Liu, J. The Vibrio H-ring facilitates the outer membrane penetration of the polar sheathed flagellum. J. Bacteriol. 2018, 200. [CrossRef]

85. Evans, D.G.; Karjalainen, T.K.; Evans, D.J., Jr.; Graham, D.Y.; Lee, C.H. Cloning, nucleotide sequence, and expression of a gene encoding an adhesin subunit protein of Helicobacter pylori. J. Bacteriol. 1993, 175, 674-683. [CrossRef] [PubMed]

86. Carlsohn, E.; Nystrom, J.; Bolin, I.; Nilsson, C.L.; Svennerholm, A.M. HpaA is essential for Helicobacter pylori colonization in mice. Infect. Immun. 2006, 74, 920-926. [CrossRef] [PubMed]

87. Hayashi, F.; Smith, K.D.; Ozinsky, A.; Hawn, T.R.; Yi, E.C.; Goodlett, D.R.; Eng, J.K.; Akira, S.; Underhill, D.M.; Aderem, A. The innate immune response to bacterial flagellin is mediated by Toll-like receptor 5. Nature 2001, 410, 1099-1103. [CrossRef]

88. Kawasaki, T.; Kawai, T. Toll-like receptor signaling pathways. Front. Immunol. 2014, 5, 461. [CrossRef] [PubMed]

89. Yoon, S.S.; Mekalanos, J.J. Decreased potency of the Vibrio cholerae sheathed flagellum to trigger host innate immunity. Infect. Immun. 2008, 76, 1282-1288. [CrossRef] [PubMed]

90. Smith, K.D.; Andersen-Nissen, E.; Hayashi, F.; Strobe, K.; Bergman, M.A.; Barrett, S.L.; Cookson, B.T.; Aderem, A. Toll-like receptor 5 recognizes a conserved site on flagellin required for protofilament formation and bacterial motility. Nat. Immunol. 2003, 4, 1247-1253. [CrossRef] [PubMed]

91. Lee, S.K.; Stack, A.; Katzowitsch, E.; Aizawa, S.I.; Suerbaum, S.; Josenhans, C. Helicobacter pylori flagellins have very low intrinsic activity to stimulate human gastric epithelial cells via TLR5. Microbes Infect. 2003, 5, 1345-1356. [CrossRef] 
92. Logan, S.M. Flagellar glycosylation-a new component of the motility repertoire? Microbiology 2006, 152, 1249-1262. [CrossRef]

93. Merino, S.; Tomas, J.M. Gram-negative flagella glycosylation. Int. J. Mol. Sci. 2014, 15, 2840-2857. [CrossRef]

94. Arora, S.K.; Neely, A.N.; Blair, B.; Lory, S.; Ramphal, R. Role of motility and flagellin glycosylation in the pathogenesis of Pseudomonas aeruginosa burn wound infections. Infect. Immun. 2005, 73, 4395-4398. [CrossRef]

95. Ewing, C.P.; Andreishcheva, E.; Guerry, P. Functional characterization of flagellin glycosylation in Campylobacter jejuni 81-176. J. Bacteriol. 2009, 191, 7086-7093. [CrossRef]

96. Guerry, P.; Ewing, C.P.; Schirm, M.; Lorenzo, M.; Kelly, J.; Pattarini, D.; Majam, G.; Thibault, P.; Logan, S. Changes in flagellin glycosylation affect Campylobacter autoagglutination and virulence. Mol. Microbiol. 2006, 60, 299-311. [CrossRef] [PubMed]

97. Hanuszkiewicz, A.; Pittock, P.; Humphries, F.; Moll, H.; Rosales, A.R.; Molinaro, A.; Moynagh, P.N.; Lajoie, G.A.; Valvano, M.A. Identification of the flagellin glycosylation system in Burkholderia cenocepacia and the contribution of glycosylated flagellin to evasion of human innate immune responses. J. Biol. Chem. 2014, 289, 19231-19244. [CrossRef] [PubMed]

98. Howard, S.L.; Jagannathan, A.; Soo, E.C.; Hui, J.P.; Aubry, A.J.; Ahmed, I.; Karlyshev, A.; Kelly, J.F.; Jones, M.A.; Stevens, M.P.; et al. Campylobacter jejuni glycosylation island important in cell charge, legionaminic acid biosynthesis, and colonization of chickens. Infect. Immun. 2009, 77, 2544-2556. [CrossRef] [PubMed]

99. Ichinose, Y.; Taguchi, F.; Yamamoto, M.; Ohnishi-Kameyama, M.; Atsumi, T.; Iwaki, M.; Manabe, H.; Kumagai, M.; Nguyen, Q.T.; Nguyen, C.L.; et al. Flagellin glycosylation is ubiquitous in a broad range of phytopathogenic bacteria. J. Gen. Plant. Path 2013, 79, 359-365. [CrossRef]

100. Schirm, M.; Soo, E.C.; Aubry, A.J.; Austin, J.; Thibault, P.; Logan, S.M. Structural, genetic and functional characterization of the flagellin glycosylation process in Helicobacter pylori. Mol. Microbiol. 2003, 48, 1579-1592. [CrossRef]

101. Logan, S.M.; Hui, J.P.; Vinogradov, E.; Aubry, A.J.; Melanson, J.E.; Kelly, J.F.; Nothaft, H.; Soo, E.C. Identification of novel carbohydrate modifications on Campylobacter jejuni 11168 flagellin using metabolomics-based approaches. FEBS J. 2009, 276, 1014-1023. [CrossRef]

102. Schirm, M.; Schoenhofen, I.C.; Logan, S.M.; Waldron, K.C.; Thibault, P. Identification of unusual bacterial glycosylation by tandem mass spectrometry analyses of intact proteins. Anal. Chem. 2005, 77, 7774-7782. [CrossRef]

103. Manning, A.J.; Kuehn, M.J. Contribution of bacterial outer membrane vesicles to innate bacterial defense. BMC Microbiol. 2011, 11, 258. [CrossRef]

104. Zhang, H.; Li, L.; Zhao, Z.; Peng, D.; Zhou, X. Polar flagella rotation in Vibrio parahaemolyticus confers resistance to bacteriophage infection. Sci. Rep. 2016, 6, 26147. [CrossRef]

105. Belas, R. Biofilms, flagella, and mechanosensing of surfaces by bacteria. Trends Microbiol. 2014, 22, 517-527. [CrossRef] [PubMed]

106. Guerrero-Ferreira, R.C.; Viollier, P.H.; Ely, B.; Poindexter, J.S.; Georgieva, M.; Jensen, G.J.; Wright, E.R. Alternative mechanism for bacteriophage adsorption to the motile bacterium Caulobacter crescentus. Proc. Natl. Acad. Sci. USA 2011, 108, 9963-9968. [CrossRef] [PubMed]

107. Baldvinsson, S.B.; Sorensen, M.C.; Vegge, C.S.; Clokie, M.R.; Brondsted, L. Campylobacter jejuni motility is required for infection of the flagellotropic bacteriophage F341. Appl. Environ. Microbiol. 2014, 80, 7096-7106. [CrossRef] [PubMed]

(C) 2020 by the authors. Licensee MDPI, Basel, Switzerland. This article is an open access article distributed under the terms and conditions of the Creative Commons Attribution (CC BY) license (http://creativecommons.org/licenses/by/4.0/). 